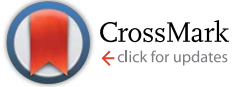

Cite this: RSC Adv., 2017, 7, 13590

Received 24th January 2017 Accepted 12th February 2017

DOI: 10.1039/c7ra01048f

rsc.li/rsc-advances

\section{Thermodynamic stabilization of semiclathrate hydrates by hydrophilic group}

\begin{abstract}
S. Muromachi, ${ }^{* a}$ R. Kamo, ${ }^{\text {}}$ T. Abe, ${ }^{\text {b }}$ T. Hiaki ${ }^{\text {b }}$ and S. Takeya ${ }^{a}$
Introducing hydrophilic groups into carboxylates is a way to modify semiclathrate hydrate frameworks and change the properties of the hydrates. In this study, we report the characterization of semiclathrate hydrates formed by tetra- $n$-butylammonium (TBA) 2-hydroxybutyrate (2HB). In addition, TBA lactate and the TBA $2 \mathrm{HB}$ salt formed stable hydrate crystals, which basically had rectangular columnar shapes. We performed equilibrium measurements and calorimetry. The melting temperature and fusion heat of the TBA $2 \mathrm{HB}$ hydrate crystals were $285.3 \mathrm{~K}$ and $177 \mathrm{~kJ} \mathrm{~kg}^{-1}$, respectively. A comparison with other carboxylate anions showed that the substitution of hydrogen atom at the 2-position in the carbon chain by a hydrophilic hydroxy group stabilizes the hydrates more than that by hydrophobic methyl group, which is the case for alcohols in clathrate hydrates. The phase equilibrium data for a number of semiclathrate hydrates were compared. A rough trend of temperature depending on type of guest anions was observed, but it is unclear if there are other correlating factors.
\end{abstract}

\section{Introduction}

Semiclathrate hydrates are host-guest compounds that are analogous crystalline materials to clathrate hydrates. ${ }^{1,2}$ Ionic guest substances, which are necessary to form semiclathrate hydrates, form hydrogen bonds with water molecules in their structures. With various ionic guest substances, the semiclathrate hydrates have a wide melting temperature range such as $270-300 \mathrm{~K}^{1-3}$ The stabilities of semiclathrate hydrates can be modified with the choice of ionic guest cation and counter anion, which are both incorporated in the hydrate structure with different coordination to the hydrate cages. This structure also provides unique properties of melting temperatures and gas capture. ${ }^{3-12}$ By the combination of ions, ${ }^{3-5}$ control of functional properties of these materials, such as melting temperature, latent heat, gas selectivity, and gas capacity, is expected. Above all, semiclathrate hydrates have attracted considerable attention as one of phase change materials for thermal storage. ${ }^{6}$

Ionic guest substances are ions of which cations usually have suitably-sized alkyl chains. Tetra- $n$-butylammonium (TBA) and tetra- $n$-butylphosphonium (TBP) cations are used widely as ionic guest molecules because of their good availability, as recently known for ionic liquids. ${ }^{7}$ The options for the counter anions vary: halogens and organic acids, such as carboxylates and hydroxycarboxylates. ${ }^{3,4}$ In the structures of semiclathrate hydrates of TBA and TBP salts, water molecules form a cage-like

${ }^{a}$ National Institute of Advanced Industrial Science and Technology (AIST), 16-1 Onogawa, Tsukuba 305-8569, Japan. E-mail: s-muromachi@aist.go.jp

${ }^{b}$ College of Industrial Technology, Nihon University, 1-2-1 Izumicho, Narashino 2758575, Japan network, such as $5^{12}, 5^{12} 6^{2}$ and $5^{12} 6^{3}$ cages, where $5^{12}$ denotes a 12-hedron composed of pentagonal faces. The TBA and TBP cations occupy a four-cage fused cage by the four butyl chains. Ionic guest anions usually form hydrogen-bonds with the host water molecules. ${ }^{1,2}$ The melting temperatures of semiclathrate hydrates may represent overall suitability of the anions including size, shape and affinity for water. With halogen anions, the melting temperatures of hydrates have clear tendencies, which decrease with increasing anion size. ${ }^{3,13}$ In the case of carboxylate anions, contrary to halogens, there is a suitable alkyl chain length for stabilization of the hydrate structure because propionate and acrylate anions provide the highest temperature. ${ }^{3,49}$ This is because the carboxy group of the carboxylate anions forms hydrogen-bonds with cage water molecules and occupies the hydrate cages. ${ }^{14-16}$ In the case of propionate and acrylate anions, the hydrophobic alkyl chain is directed at the cage centre and stabilizes the $5^{12}$ cage. ${ }^{14,16}$ With a longer alkyl chain, the carboxylate anion occupies a larger cage, such as a valerate anion incorporated in a $5^{12} 6^{2}$ cage, ${ }^{12}$ where $5^{12} 6^{2}$ denotes a 14-hedron composed of 12 pentagonal faces and 2 hexagonal faces.

In addition to the canonical clathrate hydrates, ${ }^{17,18}$ a side chain of the guest is a key to stabilizing the semiclathrate hydrates mainly because of its size and shape effects. ${ }^{1-3}$ For semiclathrate hydrates, substitutions by a methyl group at the 2-position of propionate and butyrate anions, i.e., 2-methylpropionate and 2-methylbutyrate, destabilizes the melting temperatures. ${ }^{3,4}$ With the substitution of a side chain by a hydrophilic group, the functional properties of the semiclathrate hydrates may be changed. In a previous study, we reported the incorporation of a lactate anion in the hydrate cages, 


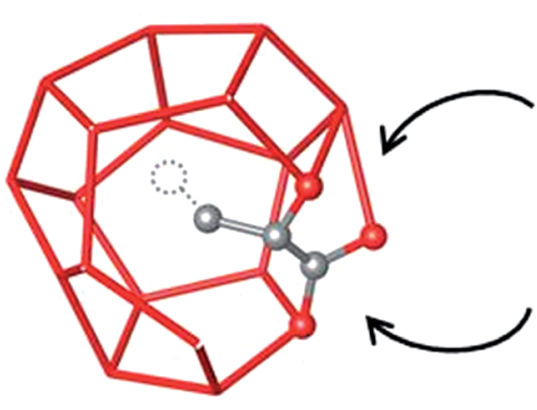

In $5^{12}$ hydrate cage

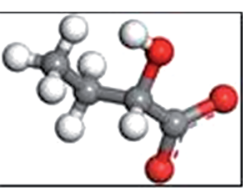

2-hydroxybutyrate

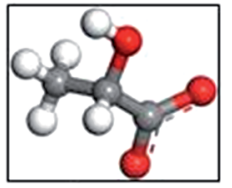

Lactate
Fig. 1 Possible coordination structure of the hydroxybutyrate anions in the $5^{12}$ cage based on the ref. 10. The structure was visualized by the VESTA program. ${ }^{19}$ The red, grey and white colours indicate oxygen, carbon and hydrogen atoms or bonds, respectively. In the $5^{12}$ hydrate cage, the atoms of the lactate anions are shown as spheres. The lattice water is only shown by bonds, and the hydrogen atoms are omitted for clarity. Herein, the methyl group of $2 \mathrm{HB}$ anion (dashed line) may be encaged.

which was a hydroxycarboxylate with a hydroxy group substituting a hydrogen at the 2-position in propionate. ${ }^{\mathbf{1 0}}$

(Fig. 1) It was found that both of the carboxy and hydroxy groups in the lactate anion formed hydrogen bonds with the water molecules of the $5^{12}$ cage. This supports the fact that hydroxy group can stabilize the semiclathrate hydrate. Owing to this coordination, the methyl group in the lactate anion showed off centred orientation in the distorted $5^{12}$ cage (Fig. 1 ). This is different from propionate and acrylate anions, of which the carbon chains are located in the centre of the $5^{12}$ cage. ${ }^{14,16}$ With a longer alkyl chain, hydroxycarboxylates may further stabilize the hydrate structure. For thermal storage applications of semiclathrate hydrates, the selection criteria of potential or promising guest molecule of semiclathrate hydrates are necessary. In this respect, knowledge of the melting temperature tendency depending on the type of guest anions is valuable. Herein, we report semiclathrate hydrates of the TBA 2-hydroxybutyrate (2HB). The $2 \mathrm{HB}$ anion has one additional alkyl chain to the lactate anion, which may stabilize the $5^{12}$ cage due to its size (Fig. 1). The thermodynamic stability of the TBA $2 \mathrm{HB}$ hydrate is discussed based on a comparison of the melting temperatures of the propionate and butyrate classes.

\section{Experimental}

\section{Materials}

We used DL-2-hydroxybutyric acid (Tokyo Chemical Industry Co., Ltd., $>95.0 \%$ ) and tetra- $n$-butylammonium hydroxide (40 mass\% solution in water, Alfa Aesar Inc.) for the synthesis of TBA 2HB. Water with a resistivity of $18.2 \mathrm{M} \Omega \mathrm{cm}$ at $298 \mathrm{~K}$ and less than $5 \mathrm{ppb}$ of total organic content was used. Tetra- $n$ butylammonium bromide (Sigma-Aldrich, Co., $>99.0 \%$ ) and $c$ hexane (Wako Pure Chemical Industries, Ltd., 99.8\%) was used as received from the provider. The TBA lactate was the same as used in a previous study. ${ }^{\mathbf{1 0}}$ For the nuclear magnetic resonance (NMR) measurements, deuterium oxide (Wako Pure Chemical
Industries, Ltd., 99.9\%) and deuteriochloroform (Wako Pure Chemical Industries, Ltd., 99.8\% containing 0.05 vol\% tetramethylsilane) were used.

\section{Synthesis and characterization of TBA $2 \mathrm{HB}$}

TBA $2 \mathrm{HB}$ aqueous solution was synthesized by the neutralization of DL-2-hydroxybutyric acid by equimolal tetra- $n$-butylammonium hydroxide. About $1 \mathrm{~g}$ of the synthesized solution was dried with the aid of an evaporator, and the water content was determined based on the mass difference between dry and wet conditions. The dried salt was mixed with a solvent and subjected to solution-state ${ }^{1} \mathrm{H}$ and ${ }^{13} \mathrm{C}$ NMR measurements to determine the ratio of the TBA cation and the $2 \mathrm{HB}$ anion. We used an NMR spectrometer (Avance 500, Bruker Biospin, Bruker Co.). The measurements were made at temperature ( $\sim 295 \mathrm{~K})$, and the number of acquisitions was 16 and 1000 for the ${ }^{1} \mathrm{H}$ and ${ }^{13} \mathrm{C}$ measurements, respectively. The spectra showed an equivalent cation to anion ratio in the synthesized solution.

\section{Phase equilibrium measurements}

We employed the optical observation method for the phase equilibrium measurements. ${ }^{10}$ The samples of TBA $2 \mathrm{HB}$ aqueous solutions were prepared with 14-different concentrations in the range of TBA 2HB mole fractions $(x)$ between 0.0029 and 0.0424 . Furthermore, $2 \mathrm{~g}$ of the solutions was injected in a glass tube sealed with a lid, and the glass tube was set in a temperaturecontrolled water bath. Once the hydrate crystals were grown at a low temperature, the system temperature was increased stepwise with a step of $0.1 \mathrm{~K}$. At each temperature step, we observed the hydrate crystals using a microscope equipped with a CCD camera. After we visually confirmed that the hydrate crystals did not melt further, we raised the system temperature. This waiting process took more than week in the longest case. The temperature before the temperature at which we observed complete dissociation of the hydrate crystals was determined to be the phase equilibrium temperature. The measurement uncertainties of the concentration and temperature were 0.0012 in mole fraction of TBA $2 \mathrm{HB}$ and $0.1 \mathrm{~K}$, respectively.

\section{DSC measurements}

The samples for the DSC measurements were aqueous solutions of TBA lactate and TBA $2 \mathrm{HB}$, which have compositions close to their hydrate crystals. After the phase equilibrium measurements, we formed TBA $2 \mathrm{HB}$ hydrate crystals in the aqueous solution with $x=0.0255$ at $282.9 \mathrm{~K}$. For TBA lactate hydrates, we formed crystals at $282.7 \mathrm{~K}$ from the aqueous solution with $x=$ 0.0228 . These crystals were melted and the solution was subjected to the DSC measurements. The compositions of the solutions were determined by the measurements of the water content by evaporation. An aqueous solution of 12-18 mg was injected in an aluminium sealing pan of which the volume was $24 \mu \mathrm{L}$. The mass of the cell was measured before and after sealing, and the mass difference was the mass of the sample. An electronic mass balance (AUW220D, Shimadzu Co.) was used, and the mass of the sample solution injected in the cell was determined within $0.0004 \mathrm{mg}$ of uncertainty. 
We used a differential scanning calorimeter (DSC-60, Shimadzu Co.). Nitrogen gas was made to flow to the measurement chamber. An empty reference cell, which was the same as sealing-type aluminium one, was used. To crystallize the sample in the first attempt, supercooling to $\sim 250 \mathrm{~K}$ was usually needed, and at this temperature, ice could also form. Therefore, we employed the annealing process ${ }^{20}$ to avoid the formation of ice in the cell. After the first crystallization, the cell temperature was raised near the melting point of the hydrate, i.e., $\sim 283 \mathrm{~K}$, and the cell was cooled again to a temperature just over $273 \mathrm{~K}$. After repeating this process a few times, we obtained good DSC curves without an ice peak. We employed a temperature increasing rate of $1 \mathrm{~K} \mathrm{~min}^{-1}$ for $c$-hexane and $2 \mathrm{~K} \mathrm{~min}^{-1}$ for the other samples. The measurements were implemented three times for a sample, and average value was obtained. The standard deviation of each measurement was less than $0.06 \mathrm{~J}$.

We used $c$-hexane for the reference, and heat of fusion was calibrated from the value $31.84 \mathrm{~kJ} \mathrm{~kg}^{-1}$ reported by Domalski. ${ }^{21}$ To check the reliability of our measurements by a comparison with the reference data, we performed DSC measurements for TBA Br hydrate. We determined the accuracy of the measurements to be $6 \mathrm{~kJ} \mathrm{~kg}^{-1}$.

\section{Results and discussion}

Results of phase equilibrium measurements are shown in Table 1 and plotted in Fig. 2. With $x=0.0029$, the equilibrium temperature was lower than the freezing point of ice. The equilibrium temperatures increased with increasing concentration. The highest equilibrium temperature, which may be equivalent to the melting temperature of the TBA $2 \mathrm{HB}$ hydrate, was $285.3 \mathrm{~K}$ at $x=0.0331$ and 0.0360 . The equilibrium temperature decreased slightly at a higher concentration, i.e., $x$ $=0.00424$. The concentrations having the highest equilibrium temperature suggest that the hydrate crystals have a hydration number of approximately 26 to 30 , which corresponds to the semiclathrate hydrate structures of cubic or tetragonal. The melting points of TBA $2 \mathrm{HB}$ hydrates are slightly higher than

Table 1 Results of phase equilibrium measurements for TBA 2HB hydrates

\begin{tabular}{lll}
\hline Mole fraction $(x)\left(\times 10^{-2}\right)$ & Mass fraction & Temperature $(\mathrm{K})$ \\
\hline 0.29 & 0.052 & 272.4 \\
0.60 & 0.104 & 273.6 \\
0.96 & 0.157 & 278.7 \\
1.36 & 0.209 & 281.5 \\
1.62 & 0.240 & 282.7 \\
1.90 & 0.271 & 283.5 \\
2.11 & 0.292 & 284.1 \\
2.32 & 0.313 & 284.4 \\
2.55 & 0.334 & 284.8 \\
2.78 & 0.355 & 284.9 \\
3.04 & 0.375 & 285.0 \\
3.31 & 0.397 & 285.3 \\
3.60 & 0.417 & 285.3 \\
4.24 & 0.459 & 284.8
\end{tabular}

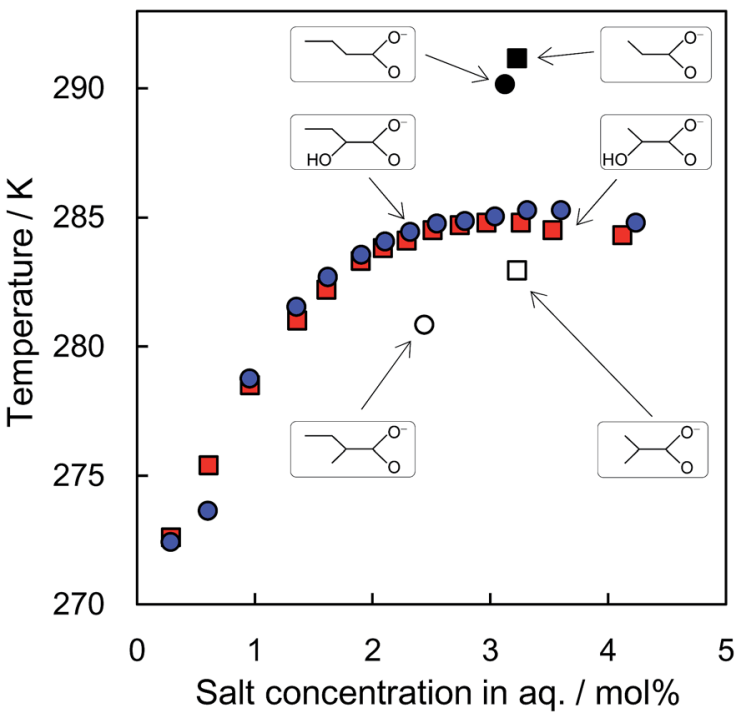

Fig. 2 Phase equilibrium data of TBA $2 \mathrm{HB}$ hydrates in comparison with the other TBA salt hydrates. $\bigcirc$ with blue, TBA 2 HB hydrate (this study); $\bigcirc$ with black, TBA butyrate; ${ }^{3} \bigcirc$ with white, TBA 2-methylbutyrate, ${ }^{3} \square$ with red, TBA lactate hydrate; ${ }^{3} \square$ with black, TBA propionate; ${ }^{3} \square$ with white, TBA 2-methylpropionate. ${ }^{3}$

those of the TBA lactate hydrates. These results suggest that the difference in carbon chain length barely affects the melting temperature.

In the literature, characterizations of semiclathrate hydrates formed with TBA propionate $(291.2 \mathrm{~K})^{3}$ and TBA butyrate (290.2 $\mathrm{K})^{3}$ were reported. The relationship of the melting point between the TBA $2 \mathrm{HB}$ hydrate and TBA lactate hydrate is similar to that between the hydrates of TBA propionate and TBA butyrate. The side chains of the both anions are substituted by a methyl group, which is in contrast to the relationship between lactate and 2-hydroxybutyrate anions., ${ }^{3,4}$ Fig. 2 compares the effects of the side chain substitution on the melting temperature and the hydrate composition. In the class of propionate, the side methyl group decreases the melting temperature with $\sim 8 \mathrm{~K}$, i.e., $291.2 \mathrm{~K}$ with propionate and $283.0 \mathrm{~K}$ with 2 -methylpropionate. The anion substituted with a hydroxy group, i.e., lactate anion, recovers the melting temperature with $\sim 2 \mathrm{~K}$ to $(284.8 \mathrm{~K})$. The butyrate class shows a different trend. The melting temperature with 2 -methylbutyrate anion $(280.9 \mathrm{~K})$ is

Table 2 Results of DSC measurements for TBA $2 \mathrm{HB}$ and TBA lactate hydrates

\begin{tabular}{llll}
\hline & $\begin{array}{l}\text { Ionic guest concentration } \\
\text { in hydrate crystal } \\
\text { (mass fraction) }\end{array}$ & \multicolumn{2}{l}{ Heat of fusion } \\
\cline { 3 - 4 } Ionic guest & $\mathrm{kJ} \mathrm{kg}^{-1}$ & $\mathrm{~kJ} \mathrm{~kg}_{\text {(water) }}{ }^{-1}$ \\
\hline TBA 2HB & $0.396^{a}$ & 177 & 294 \\
TBA lactate & $0.369^{a}$ & 191 & 303 \\
TBA Br & $0.408^{b}$ & 193 & 323
\end{tabular}

${ }^{a}$ Determined from the masses between wet and dry conditions with the aid of evaporator. ${ }^{b}$ Gravimetrically prepared to be the same composition as reported in the ref. 20, 22 and 23. 
$\sim 10 \mathrm{~K}$ lower than that with butyrate $(290.2 \mathrm{~K})$. The hydration numbers also differ, i.e., 40 with 2-methylbutyrate and 31 with butyrate, which suggests that the substituted methyl group modifies and destabilizes the hydrate structure. ${ }^{3}$ As is the case in the propionate class, the presently used $2 \mathrm{HB}$ anion recovered the melting temperature to $285.3 \mathrm{~K}$, but with a larger degree, i.e., $\sim 4 \mathrm{~K}$, which is the same level as the melting temperature of TBA lactate hydrate.

Two types of crystal morphologies of the TBA $2 \mathrm{HB}$ hydrates were observed during the phase equilibrium measurements: rectangular-columnar crystals and block crystals at $\sim 283 \mathrm{~K}$. With $x=0.0211$, two different morphologies, i.e., thin and thick columnar crystals, were observed (Fig. 3A). With $x=0.0232$, thick rectangular-columnar crystals were obtained (Fig. 3B). With $x=0.0255$, columnar-rectangular crystals and block crystals both formed (Fig. 3C). With $x=0.0360$, both crystals were observed, but the block type crystal appeared dominant in this system (Fig. 3D).

We performed single crystal X-ray diffraction on the same crystal as that for the DSC measurements by the method used in our earlier study. ${ }^{10}$ The present preliminary structure analysis showed the tetragonal structure with unit cell parameters for $a=23.3850 \AA$ and $c=24.4019 \AA$ and a possible space group $P \overline{4}$. This unit cell is twice the size of that of the TBA lactate hydrate with $a=23.361$ and $c=12.248 .^{10}$ The present diffraction data were not sufficient for structure refinement analysis, but they showed the tetragonal hydrate structure. This means that the 2HB anion slightly modified host water cages from those of the TBA lactate hydrate due to the longer carbon chain. Specifically, the cell extended $0.1 \%$ in the direction of the $a$-axis and shortened $0.4 \%$ in the direction of $c$-axis due to the change from TBA lactate to TBA $2 \mathrm{HB}$.

Table 2 summarizes the results of DSC measurements. Fig. 4 shows that the DSC data for TBA Br hydrate with $x=0.0370$ ( 0.408 in mass fraction) was $193 \mathrm{~kJ} \mathrm{~kg}^{-1}$. Although there may be a minor peak before the major peak, which suggests the sample was a bi-phase, the fusion heat of the TBAB hydrates agreed well

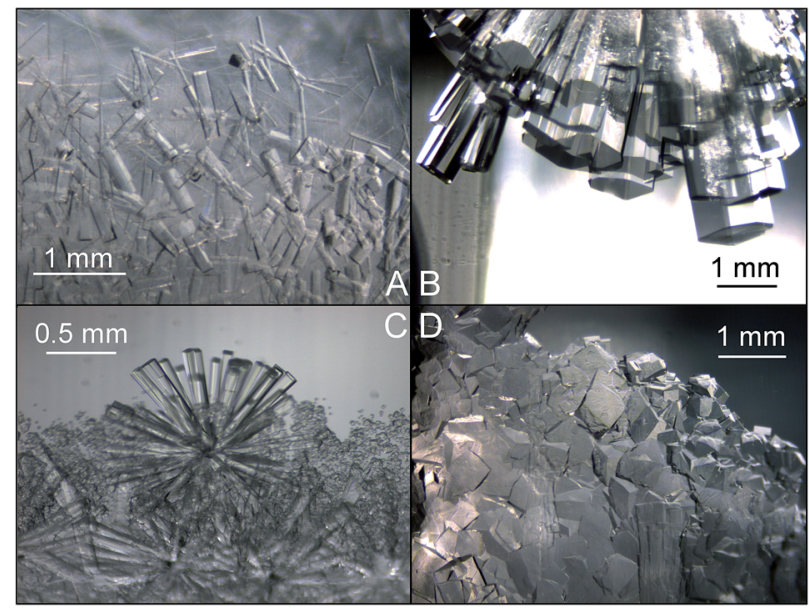

Fig. 3 Crystal morphologies of TBA $2 \mathrm{HB}$ hydrates. (A) $x=0.0211$ at $283.2 \mathrm{~K}$; (B) $x=0.0232$ at $283.2 \mathrm{~K}$; (C) $x=0.0255$ at $282.9 \mathrm{~K}$; (D) $x=$ 0.0360 at $283.0 \mathrm{~K}$.

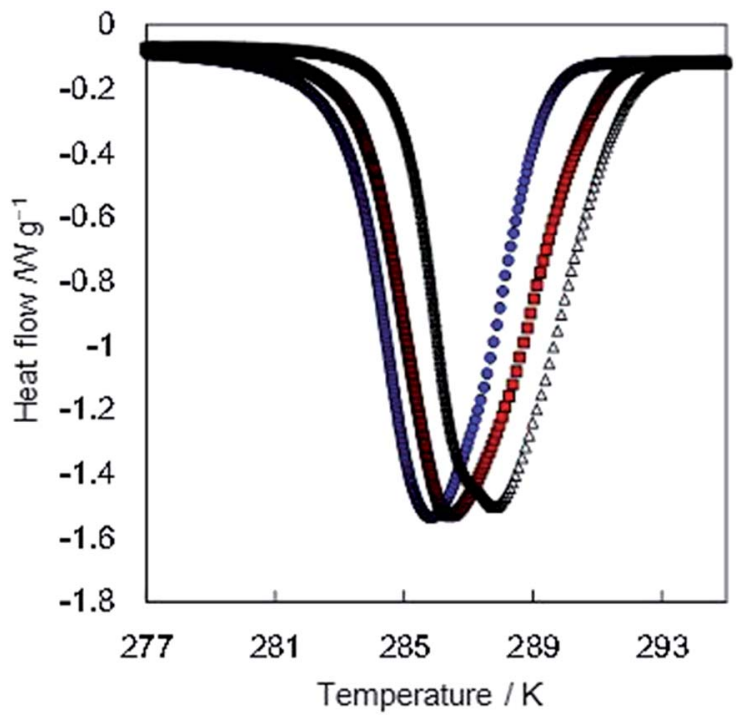

Fig. 4 DSC curves for the TBA lactate and TBA 2HB hydrates. $\bigcirc$ with blue, TBA 2 HB hydrate; $\square$ with red, TBA lactate; $\triangle$, TBA Br hydrate.

with the ref. 20, 22 and 23. The DSC curves of TBA $2 \mathrm{HB}$ hydrate and TBA lactate hydrate had similar peak depths to those of the TBA Br hydrate, but the heats of fusion for TBA $2 \mathrm{HB}$ and TBA lactate were significantly different, i.e., 177 and $191 \mathrm{~kJ} \mathrm{~kg}^{-1}$, respectively.

The mass fractions of the TBA $2 \mathrm{HB}$ solutions determined by evaporation were 0.396 . This suggests a hydration number of approximately 30 , which agreed with the value suggested by the phase equilibrium data. The dried sample analysed by ${ }^{1} \mathrm{H}$ NMR spectroscopy showed that the ratios of the cation to the anion corresponded to $1: 1$ both in the hydrate crystals of TBA $2 \mathrm{HB}$ and TBA lactate.

The results obtained in this study suggest that an extraordinarily large and heavy anion can be incorporated in the hydrate cage by introducing a hydrophilic hydroxy group. The difference in carbon chain length of the ionic guest anion modified the melting temperature. This is not the case with clathrate hydrates, such as hydrocarbons and alcohols, which basically destabilize the structure. ${ }^{18,24}$ Further studies on ionic guests will give a variety of the properties of semiclathrate hydrates.

\section{Conclusions}

In this study, we investigated the modification of the thermodynamic stability of tetra- $n$-butylammonium (TBA) salt hydrates by hydroxycarboxylate anions. The 2-hydroxybutyrate (2HB) anion, which has one additional methyl group to lactate, formed ionic clathrate hydrates with the tetra- $n$-butylammonium cation. The crystal morphologies suggested mainly two different crystal structures. The melting temperature of the TBA $2 \mathrm{HB}$ hydrate was $285.3 \mathrm{~K}$, which is close to that of the TBA lactate hydrate. In contrast, the heat of fusion was significantly lower than that of the TBA lactate hydrate and TBA Br hydrate. The single crystal X-ray diffraction analysis for the TBA $2 \mathrm{HB}$ 
hydrate showed the modification of the unit cell from that of TBA lactate hydrate. A comparison with 2-methylcarboxylate anions showed that the introduction of hydroxy group to the ionic guest anion recovered the melting temperatures of the hydrates, and hence, the stability, from substitution by a hydrophobic methyl group. The present study showed a way to modify the thermodynamic properties of semiclathrate hydrates by the functional group of an ionic guest.

\section{Acknowledgements}

SM thanks Grant-in-Aid for Young Scientists (B) from the Ministry of Education, Culture, Sports, Science, and Technology of Japan (No. 26820069). We thank Takuma Nukazawa for his help on the DSC measurements, Dr Motoi Oshima and Michika Ohtake for their kind advices on DSC measurements, and Dr Yoshitaka Yamamoto for discussion.

\section{Notes and references}

1 Y. A. Dyadin and K. A. Udachin, J. Struct. Chem., 1987, 28, 75. 2 G. A. Jeffrey, in Inclusion Compounds, ed. J. L. Atwood, J. E. D. Davies and D. D. MacNicol, Academic Press, London, 1984, vol. 1 , ch. 5 .

3 H. Nakayama and S. Torigata, Bull. Chem. Soc. Jpn., 1984, 57, 171. 4 Y. A. Dyadin, L. A. Gaponenk, L. S. Aladko and S. V. Bogatyryova, J. Inclusion Phenom., 1984, 2, 259.

5 S. Muromachi and S. Takeya, Fluid Phase Equilib., DOI: 10.1016/j.fluid.2017.01.008.

6 S. Wenji, X. Rui, H. Chong, H. Shihui, D. Kaijun and F. Ziping, Int. J. Refrig., 2009, 32, 1801; P. Zhang, Z. W. Ma and R. Z. Wang, Renew. Sustain. Energy Rev., 2010, 14, 598; H. Kumano, T. Hirata and T. Kudoh, Int. J. Refrig., 2011, 34, 1963; J. Douzet, M. Kwaterski, A. Lallemand, F. Chauvy, D. Flick and J.-M. Herri, Int. J. Refrig., 2013, 36, 1616.

7 N. V. Plechkova and K. R. Seddon, Chem. Soc. Rev., 2008, 37, 123. 8 A. Chapoy, R. Anderson and B. Tohidi, J. Am. Chem. Soc., 2007, 129, 746; N. H. Duc, F. Chauvy and J.-M. Herri, Energy Convers. Manage., 2007, 48, 1313; D. Zhong and P. Englezos, Energy Fuels, 2012, 26, 2098; N. Ye and P. Zhang, J. Chem. Eng. Data, 2014, 59, 2920.

9 H. Sakamoto, K. Sato, K. Shiraiwa, S. Takeya, M. Nakajima and R. Ohmura, RSC Adv., 2011, 1, 315.
10 S. Muromachi, T. Abe, Y. Yamamoto and S. Takeya, Phys. Chem. Chem. Phys., 2014, 16, 21467.

11 S. Muromachi, K. A. Udachin, K. Shin, S. Alavi, I. L. Moudrakovski, R. Ohmura and J. A. Ripmeester, Chem. Commun., 2014, 50, 11476.

12 S. Muromachi, K. A. Udachin, S. Alavi, R. Ohmura and J. A. Ripmeester, Chem. Commun., 2016, 52, 5621.

13 T. Kobori, S. Muromachi, T. Yamasaki, S. Takeya, Y. Yamamoto, S. Alavi and R. Ohmura, Cryst. Growth Des., 2015, 15, 3862.

14 V. Y. Komarov, T. V. Rodionova and K. Suwinska, J. Struct. Chem., 2012, 53, 768.

15 T. Rodionova, V. Komarov, J. Lipkowski and N. Kuratieva, New J. Chem., 2010, 34, 432.

16 S. Muromachi, M. Kida, S. Takeya, Y. Yamamoto and R. Ohmura, Can. J. Chem., 2015, 93, 954.

17 K. Tezuka, K. Murayama, S. Takeya, S. Alavi and R. Ohmura, J. Phys. Chem. C, 2013, 117, 10473; K. Yasuda, Ind. Eng. Chem. Res., 2009, 48, 9335; O. S. Rouher and A. J. Barduhn, Desalination, 1969, 6, 57; S. Takeya, H. Fujihisa, A. Hachikubo, H. Sakagami and Y. Gotoh, Chem.-Eur. J., 2014, 20, 17207; M. Kida, H. Sakagami, M. Watanabe, Y. Jin, N. Takahashi and J. Nagao, Chem. Eng. Sci., 2016, 140, 10; H. Youn, M. Cha and H. Lee, ChemPhysChem, 2015, 16, 2876.

18 K. A. Udachin, S. Alavi and J. A. Ripmeester, J. Chem. Phys., 2011, 134, 121104.

19 K. Momma and F. Izumi, J. Appl. Crystallogr., 2011, 44, 1272. 20 M. Oshima, M. Kida, Y. Jin and J. Nagao, J. Chem. Thermodyn., 2015, 90, 277.

21 E. S. Domalski and E. D. Hearing, J. Phys. Chem. Ref. Data, 1996, 25, 1.

22 W. Lin, D. Dalmazzone, W. Fürst, D. Anthony, L. Fournaison and P. Clain, Fluid Phase Equilib., 2014, 372, 63.

23 H. Oyama, W. Shimada, T. Ebinuma, Y. Kamata, S. Takeya, T. Uchida, J. Nagao and H. Narita, Fluid Phase Equilib., 2005, 234, 131.

24 S. Alavi, R. Ohmura and J. A. Ripmeester, J. Chem. Phys., 2011, 134, 054702; K. Shin, K. A. Udachin, I. L. Moudrakovski, D. M. Leek, S. Alavi, C. I. Ratcliffe and J. A. Ripmeester, Proc. Natl. Acad. Sci. U. S. A., 2013, 110, 8437. 